\title{
Influence of flowable composite liner on the microleakage of posterior packable resin Composites - An in vitro study
}

\author{
Mrunal Manohar Shinde1,", Sharad Basavraj Kamat ${ }^{2}$ \\ ${ }^{\mathbf{1}}$ Assistant Professor, ${ }^{2}$ Professor \& HOD, Dept. of Conservative Dentistry \& Endodontics, ${ }^{\mathbf{1}}$ Bharati Vidhyapeeth Deemed to be \\ University Dental College \& Hospital, Pune, Maharashtra, ${ }^{2}$ Bharati Vidhyapeeth Deemed to be University Dental College \& \\ Hospital, Sangli, Maharashtra, India
}

*Corresponding Author:

Email: mrunal821@gmail.com

\begin{abstract}
Introduction: The aim of this study was to investigate the influence of flowable composite intermediary liner on the microleakage between the tooth tissue and the packable composite resin.

Materials and Methods: Forty mandibular molars, each prepared with two class II cavities were randomly divided in two groups: In group A one side was restored with Solitaire (KULZER); the other side was lined with Charisma flow (KULZER) and then restored with Solitaire. In group B one side was restored with Filtek p60 (3M); the other side was lined with Filtek flow $(3 \mathrm{M})$ and then restored with Filtek p60. Teeth were then thermocycled for 1000 cycle at $5^{\circ}$ and $55^{\circ}$ and immersed in a solution of $0.5 \%$ basic fuschin dye for 24 hours. Embedded specimens were sectioned longitudinally. Cervical and occlusal microleakage was measured by the extent of dye penetration.

Results: Statistically in both groups, microleakge was more in the cavities that were not lined with flowable composites and the cervical margins showed more amount of microleakage as compared to occlusal margins with and without liner. Overall there was no significant difference in the amount of leakage among the two companies at cervical and occlusal margins, with and without flowable liner.

Conclusion: Microleakge was more in the cavities that were not lined with flowable composites as compared to cavities lined with flowable composite both in occlusal and cervical margins. The cervical margins showed more amount of microleakage as compared to occlusal margins with and without liner.
\end{abstract}

Keyword: Microleakge, Flowable composite, Packable composite.

\section{Introduction}

Increasing demands for esthetic restoration, public concern related to mercury in dental amalgam, wear resistance and adhesion techniques have resulted in increased interest in composite resin as an alternative posterior restorative material. ${ }^{1}$

Traditional composite resins have never been the ideal amalgam substitute. Resin composites require more time to place compared to amalgam and are more difficult to manipulate. ${ }^{1}$

To counter these problems, more recently composites have been developed by densely loading fillers into hybrid composites known as condensable or packable composites. These packable composites are found to provide decreased wear, increased stiffness, resistance to condensation forces and establishment of optimal proximal contact. ${ }^{1}$ Despite the advantages of packable composites, ability of these stiffer materials to adequately adapt to internal areas and cavosurface margins, particularly at the cervical areas make posterior composite restoration technique sensitive. ${ }^{3}$

To address the shortcomings an intermediate layer of restorative material has been suggested as a liner beneath packable composite known as flowable composite.

Flowable resin composites have low viscosity, increased elasticity and wettability. Being less viscous, it improves the wettability by flowing onto all prepared surfaces creating an intimate union with the microstructural defects in the floor and the walls of the cavity preparation, thereby improving final marginal integrity. They also act as a flexible intermediate layer that helps relieve stresses during polymerization shrinkage of the restorative resin. These characteristics and a syringe delivery system make them an ideal choice for the use as a liner beneath packable composite. $^{3}$

Hence, the purpose of this in vitro study was to investigate the influence of flowable composite intermediary liner on the microleakage between the tooth tissue and the packable composite resin and to compare the extent of micro leakage at the occlusal and cervical margins in class II packable composite restoration with and without flowable liner.

\section{Materials and Methods}

Source of data: The study was conducted in the Department of Conservative Dentistry \& Endodontics, Bharati Vidyapeeth Deemed University, Dental College \& Hospital, Sangli.

\section{Method of collection of data}

Inclusion criteria: Forty extracted human permanent mandibular molar teeth free of cracks, caries and fractures were selected for the in vitro study. 
Exclusion criteria: Teeth having cervical caries and severe coronal caries were not included in this study.

Methodology: Forty extracted, non-carious mandibular molars were stored in $0.2 \%$ sodium azide at room temperature. Samples were stored in distilled water at room temperature following cleaning and throughout the experiment.

Tooth Preparation: Two class II preparations were made on each tooth, one on the mesial surface and one on the distal surface, with a high-speed handpiece using air water spray and 256 carbide bur (S.S. White, USA). At least $1.5 \mathrm{~mm}$ of sound tooth structure was left occlusally between the two cavities. Pulpal floor depth was $2.0 \mathrm{~mm}$ and the proximal boxes were approximately $4.0 \mathrm{~mm}$ in height, $4.0 \mathrm{~mm}$ in width and 1.0 to $1.5 \mathrm{~mm}$ deep. The cervical margin was placed in cementum 1.0 to $1.5 \mathrm{~mm}$ apical to the CEJ. Forty teeth with two preparations per tooth were randomly assigned into two groups, 40 preparations per group.

Restoration Placement: Each tooth was etched and the recommended bonding agent was applied and light cured. A stainless steel matrix (Tofflemire) was then adapted to the prepared tooth before incremental insertion and light curing of the restorative material. Where a liner application was randomized, it was placed prior to the packable composite and light cured. All materials were light cured as per manufacturers' instructions using a light curing unit (Unicorn).

Group A: One side was restored with Solitaire (KULZER); the other side was lined with Charisma flow (KULZER) and then restored with Solitaire. The bonding agent used was Gluma comfort bond plus (KULZER) as follows:

Samples were total etched with $37.5 \%$ phosphoric acid for 15 seconds. Preparations were rinsed thoroughly with water and lightly air dried for two seconds. Gluma Comfort Bond Plus bonding agent was applied using a light brushing motion with the applicator tip for 10 seconds, air thinned for three seconds and light cured for 20 seconds. On one side of prepared cavity, 1-mm liner of Charisma Flow was placed in the base of proximal box, axial wall and pulpal floor, then light cured for 40 seconds. Solitaire packable composite was placed in 2-mm increments and polymerized for 40 seconds. Other side of prepared cavity was restored with only incremental layer of
Solitaire packable composite and light cured for 40 seconds.

Group B: The restoration procedure was same as in group A. One side was restored with Filtek p60 (3M); the other side was lined with Filtek flow (3M) and then restored with Filtek p60. The bonding agent used was Scothbond (3M).

Thermocycling: The specimens were then thermocycled in $5^{\circ} \mathrm{C}$ and $55^{\circ} \mathrm{C}$ water with a one-minute dwell time for 1,000 cycles.

Dye Penetration: Following thermocycling, the apex of each tooth was sealed with epoxy cement and the tooth was painted with two coats of fingernail varnish to within $1 \mathrm{~mm}$ of the restoration margins. Specimens were placed in a solution of $0.5 \%$ basic fuschin dye for 24 hours.

Sectioning: Embedded specimens were sectioned longitudinally through their centers mesial to distal using a hard tissue microtome to produce multiple sections. Dye penetration was measured at the cervical and occlusal margins of all restorations. The extent of microleakage was determined visually under a stereomicroscope at 40x. Two examiners scored the extent of dye penetration using ordinal scale (0-4) according to the Scoring criteria given in (Fig. 1).

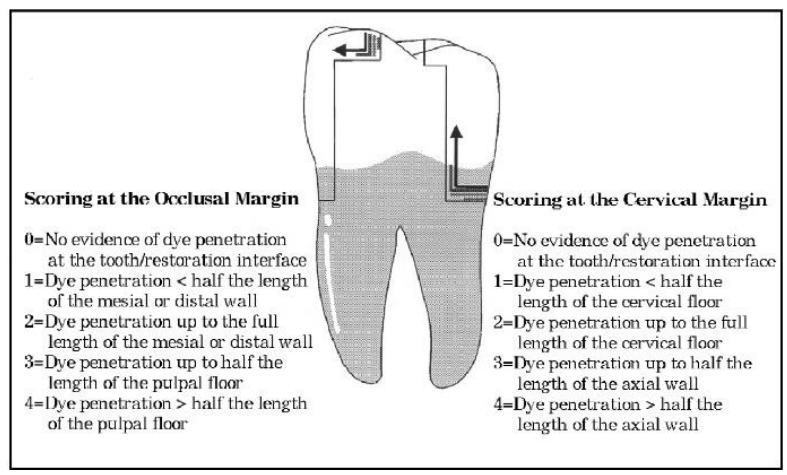

Fig. 1: Scoring criteria for dye penetration

\section{Statistical Analysis}

Descriptive statistics was applied to asses mean and standard deviation of microleakage, 'unpaired $t$ test' was used to compare microleakge between composite of kulzer and 3M Companies and also between packable and packable/flowable in both brands. 


\section{Results}

Table 1: Illustrates comparison between composites of two companies (3M and kulzer) at both cervical and occlusal level. Overall there was no significant difference in the amount of leakage among the two companies at cervical and occlusal margins, with and without flowable liner

\begin{tabular}{|c|c|c|c|c|c|c|}
\hline & Group & $\mathbf{N}$ & Mean & SD & t value & $P$ value \\
\hline \multirow{2}{*}{$\begin{array}{l}\mathrm{P}+\mathrm{F} \\
\text { Cervical }\end{array}$} & Kulzer & 20 & 1.95 & 0.686 & \multirow{2}{*}{0.402} & \multirow{2}{*}{0.690} \\
\hline & 3M ESPE & 20 & 1.85 & 0.875 & & \\
\hline \multirow{2}{*}{$\begin{array}{l}\mathrm{P}+\mathrm{F} \\
\text { occlusal }\end{array}$} & Kulzer & 20 & 1.15 & 0.813 & \multirow{2}{*}{0.529} & \multirow{2}{*}{0.600} \\
\hline & 3M ESPE & 20 & 1.00 & 0.973 & & \\
\hline \multirow{2}{*}{ P Cervical } & Kulzer & 20 & 3.55 & 0.759 & \multirow{2}{*}{1.388} & \multirow{2}{*}{0.173} \\
\hline & 3M ESPE & 20 & 3.20 & 0.834 & & \\
\hline \multirow{2}{*}{ P occlusal } & Kulzer & 20 & 1.70 & 0.657 & \multirow{2}{*}{-0.565} & \multirow{2}{*}{0.575} \\
\hline & 3M ESPE & 20 & 1.85 & 0.988 & & \\
\hline
\end{tabular}

Table 2: Describes micro leakage of each material at cervical and occlusal margin, with and without flowable liner. In group A and group B samples, cervical margin had significantly higher micro leakage GROUP A $[\mathrm{P}=0.002 ; \mathrm{P}=0.000]$, GROUP B $[\mathrm{P}=0.006 ; \mathrm{P}=0.000]$

\begin{tabular}{|c|c|c|c|c|c|c|c|}
\hline & & Group & $\mathbf{N}$ & Mean & SD & t value & $P$ value \\
\hline \multirow{4}{*}{$\begin{array}{c}\text { Group } \\
\text { A }\end{array}$} & \multirow{2}{*}{$\mathrm{P}+\mathrm{F} \_\mathrm{K}$} & Cervical & 20 & 1.95 & .686 & \multirow{2}{*}{3.363} & \multirow{2}{*}{0.002} \\
\hline & & Occlusal & 20 & 1.15 & 0.813 & & \\
\hline & \multirow{2}{*}{$\mathrm{P} \_\mathrm{K}$} & Cervical & 20 & 3.55 & .759 & \multirow{2}{*}{8.241} & \multirow{2}{*}{0.000} \\
\hline & & Occlusal & 20 & 1.70 & .657 & & \\
\hline \multirow{4}{*}{$\begin{array}{c}\text { Group } \\
\text { B }\end{array}$} & \multirow{2}{*}{$\mathrm{P}+\mathrm{F} \_3 \mathrm{M}$} & Cervical & 20 & 1.85 & .875 & \multirow{2}{*}{2.904} & \multirow{2}{*}{0.006} \\
\hline & & Occlusal & 20 & 1.00 & .973 & & \\
\hline & \multirow{2}{*}{$\mathrm{P} \_3 \mathrm{M}$} & Cervical & 20 & 3.20 & .834 & \multirow{2}{*}{4.670} & \multirow{2}{*}{0.000} \\
\hline & & Occlusal & 20 & 1.85 & .988 & & \\
\hline
\end{tabular}

Table 3: Demonstrates micro leakage in cavities, one which is lined with flowable composite and one which is not lined with flowable composite. In group A and group B samples, Cavities restored only with packable composite had significantly higher micro leakage than cavities lined with fluid composite. GROUP A $[P=0.006 ; P=0.024]$, GROUP B $[P=0.000 ; P=0.009]$

\begin{tabular}{|c|c|c|c|c|c|c|c|}
\hline & & Group & $\mathbf{N}$ & Mean & SD & t value & $P$ value \\
\hline \multirow{4}{*}{$\begin{array}{c}\text { Group } \\
\mathrm{A}\end{array}$} & \multirow{2}{*}{ Cervical_K } & $\mathrm{P}+\mathrm{F}$ & 20 & 1.95 & .686 & \multirow{2}{*}{-6.992} & \multirow{2}{*}{.000} \\
\hline & & $\mathrm{P}$ & 20 & 3.55 & .759 & & \\
\hline & \multirow{2}{*}{ occlusal_K } & $\mathrm{P}+\mathrm{F}$ & 20 & 1.15 & .813 & \multirow{2}{*}{-2.354} & \multirow{2}{*}{.024} \\
\hline & & $\mathrm{P}$ & 20 & 1.70 & .657 & & \\
\hline \multirow{4}{*}{$\begin{array}{c}\text { Group } \\
\text { B }\end{array}$} & \multirow{2}{*}{ cervical_3M } & $\mathrm{P}+\mathrm{F}$ & 20 & 1.85 & .875 & \multirow{2}{*}{-4.996} & \multirow{2}{*}{.000} \\
\hline & & $\mathrm{P}$ & 20 & 3.20 & .834 & & \\
\hline & \multirow{2}{*}{ occlusal_3M } & $\mathrm{P}+\mathrm{F}$ & 20 & 1.00 & .973 & \multirow{2}{*}{-2.741} & \multirow{2}{*}{.009} \\
\hline & & $\mathrm{P}$ & 20 & 1.85 & .988 & & \\
\hline
\end{tabular}

Discussion

Overall the results of this study revealed:

1. Less microleakage in cavities lined with flowable composite in both groups, can be attributed to: Thickness of the flowable liner eliminates the problem of oxygen inhibition, thereby helping to establish a strong and durable bond to dentin. ${ }^{7}$

Low modulus of elasticity, increased wettability, non-stickiness, and fluid injectability of fluid composites may be useful in absorbing stresses and reducing microleakage caused by polymerization shrinkage. ${ }^{6}$

The use of flowable materials as a liner underneath the resin composites may reduce the effects of the
C-factor (the C-factor being the ratio of bonded to unbonded surfaces). ${ }^{5}$

2. Increased amount of microleakage at cervical/occlusal areas in cavities restored with packable composite without use of flowable composite may be due to:

These stiffer materials may not adequately adapt to internal areas and cavosurface margins, particularly at the cervical joint. ${ }^{6}$

Packable composites with increased modulus of elasticity present, greater problems related to voids and prevent complete wetting of cavity wall during placement. ${ }^{6}$

3. More amount of microleakge at cervical margin than occlusal margin in both groups may be reasoned to: 
Bond strength to enamel is usually higher than the bond strength to dentin as dentin is a less favourable bonding substrate compared to enamel. ${ }^{1}$

\section{Conclusion}

Within limitations, present study concluded that:

1. Microleakge was more in the cavities that were not lined with flowable composites as compared to cavities lined with flowable composite both in occlusal and cervical margins.

2. Cervical margins showed more amount of microleakage as compared to occlusal margins with and without liner.

\section{References}

1. Leevailoj C, Cochran MA, Matis BA, Moore BK et al. Microleakage of posterior packable resin composites with and without flowable liners. Oper Dent. 2001 MayJun;26(3):302-7.

2. Tredwin CJ, Stokes A, Moles DR. Influence of flowable liner and margin location on microleakage of conventional and packable class II resin composites. Oper Dent. 2005 Jan-Feb;30(1):32-8.

3. Majety KK, Pujar M. In vitro evaluation of microleakage of Class II packable composite resin restorations using flowable composite and resin modified glass ionomers as intermediate layers. J Conserv Dent 2011;14:414-7.

4. Neme AM, Maxson BB, Pink FE, Aksu

MN.Microleakage of Class II packable resin composites lined with flowables: an in vitro study. Oper Dent. 2002 Nov-Dec; 27(6):600-5.

5. Sadeghi M, Lynch CD. The effect of flowable materials on the microleakage of Class II composite restorations that extend apical to the cemento-enamel junction. Oper Dent. 2009 May-Jun;34(3):306-11.

6. Sadeghi M (2007) The effect of fluid composite as gingival layer on microleakage of Class II composite restorations Dental Research Journal 4(1)40-7.

7. Cho E, Chikawa H, Kishikawa R, Inai $\mathrm{N}$ et al. Influence of elasticity on gap formation in a lining technique with flowable composite. Dent Mater J. 2006 Sep;25(3):53844.

8. Estafan AM, Estafan D. Microleakage study of flowable composite resin systems. Compend Contin Educ Dent. 2000 Sep;21(9):705-8.

9. Chuang SF, Liu JK, Chao CC, Liao FP et al. Effects of flowable composite lining and operator experience on microleakage and internal voids in class II composite restorations. J Prosthet Dent. 2001 Feb;85(2):177-83.

10. Meiers JC, Kazemi R, Meier CD. Microleakage of packable composite resins. Oper Dent. 2001; 26:121-6.

11. Jang KT, Chung DH, Shin D, García-Godoy F. Effect of eccentric load cycling on microleakage of Class $\mathrm{V}$ flowable and packable composite resin restorations. Oper Dent. 2001 Nov-Dec; 26(6):603-8. 